\title{
Correction: Difference in levels of SARS-CoV-2 S1 and S2 subunits- and nucleocapsid protein-reactive SlgM/lgM, lgG and SlgA/lgA antibodies in human milk
}

\author{
Veronique Demers-Mathieu (D) - Dung M. Do - Gabrielle B. Mathijssen - David A. Sela (D) Antti Seppo •
} Kirsi M. Järvinen • Elena Medo

Published online: 16 September 2020

(c) The Author(s), under exclusive licence to Springer Nature America, Inc. 2020

Correction to: Journal of Perinatology

https://doi.org/10.1038/s41372-020-00805-w
The original version of this article contained an error in the spelling of the author D.M. Do, which was incorrectly given as M. Dung. This has now been corrected in both the PDF and HTML versions of the article. 